\title{
Application of Cloud Computing for Smart Cities Project
}

\author{
Debasis Sarkar ${ }^{1}$, Hariom Thaker $^{2}$ \\ Associate Professor and Head, Dept. of Civil Engineering, School of Technology, Pandit Deendayal Petroleum \\ University, Gandhinagar, Gujarat, India ${ }^{1}$ \\ Former M. Tech Student, Infrastructure Engineering \& Management, Pandit Deendayal Petroleum University, \\ Gandhinagar $^{2}$
}

\begin{abstract}
Concept of cloud computing relevant to smart city was started with understanding the information management in construction projects. This paper is an attempt to explore the potential applications of cloud computing in a smart cities project. Relative Importance Index (RII) analysis was carried out to find out the critical parameters which can be helpful to establish a framework for development of smart city. Amongst the identified critical parameters it has been observed that application of mobile phones or mobile apps can be very effective for real time monitoring of the work progress which is helpful to minimize the time and effort for monitoring an activity associated with the development of the smart city project. It helps Government organization in different tasks to reduce time and cost for development of smart cities. This application is run through cloud because daily huge data feeds in this application and data mining is easily done in different sectors of smart city. For a smart city project which may be primarily multidisciplinary in nature these applications are helpful to improve the project coordination, project collaboration, for generating accurate real time project data and also for identification of project specific information which might be useful in implementation of the project.
\end{abstract}

Keywords: Cloud Computing, Smart cities, Real time monitoring, Process flow, Mobile application.

\section{INTRODUCTION}

Cloud computing is a general term for anything that involves delivering hosted services over the Internet. Cloud computing relies on sharing of resources to achieve coherence and economies of scale, similar to a utility over a network. The cloud approach, in which providers outside city government deliver a technological platform for gathering and mining data and producing city applications over the public internet or a virtual private network has become the favoured means for municipalities to move to the next level. Smart cities encompass services in diverse business and technological domains. Presently, most of these services are delivered through domain-specific, tightly coupled systems provided by specific vendors, which entail limited scalability and extensibility. This research work is an attempt to explore the potentialities of application of cloud computing to digitize smart city projects.

\section{LITERATURE REVIEW}

Nowicka (2014) has described in "Smart City logistics on cloud computing model" that city developing in sustainable manner is most competitive when it meets citizen's demands. One of the easiest methods to help understand the residents' needs can be crowd sourcing usage. However the most challenging area of responsibility is to manage traffic by the city logistics infrastructure designed to eliminate congestion problems within existing city spatial and, at the same time, to flexibly reply on transport changing demands.

Rawai (2013) has discussed about Cloud Computing for green construction management. According to them integrated information, innovation and collaboration are the key factors for the sustainable development of construction organizations. The advancement of cloud computing technology offers construction organizations great potential for developing a collaborative and integrated environment for construction management. Figure 1 represents the types of cloud computing platforms available.

According to Rawai (2013) "Big Data" cognition has become a dominant problem in interactive visual analytics for event detection and response, metereology, cosmology, and large smart city applications including traffic monitoring and management, search and rescue operations, crowd management and logistics. The main problems are mainly due to big data volume and velocity and, in some cases, variety in both dimension and type. Figure 2 represents the "Cloudet Architecture" as proposed by Rawai (2013). 

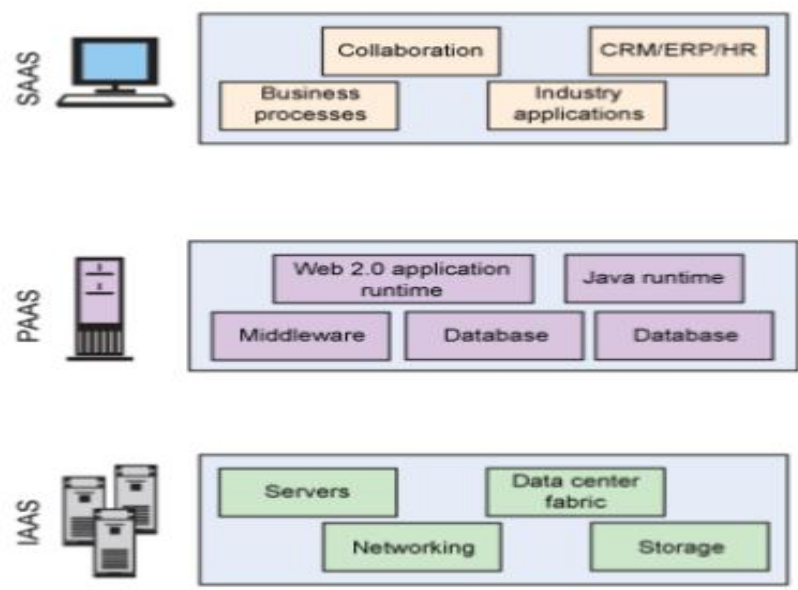

Figure 1: Types of Cloud Computing Platforms (Rawai, 2013)

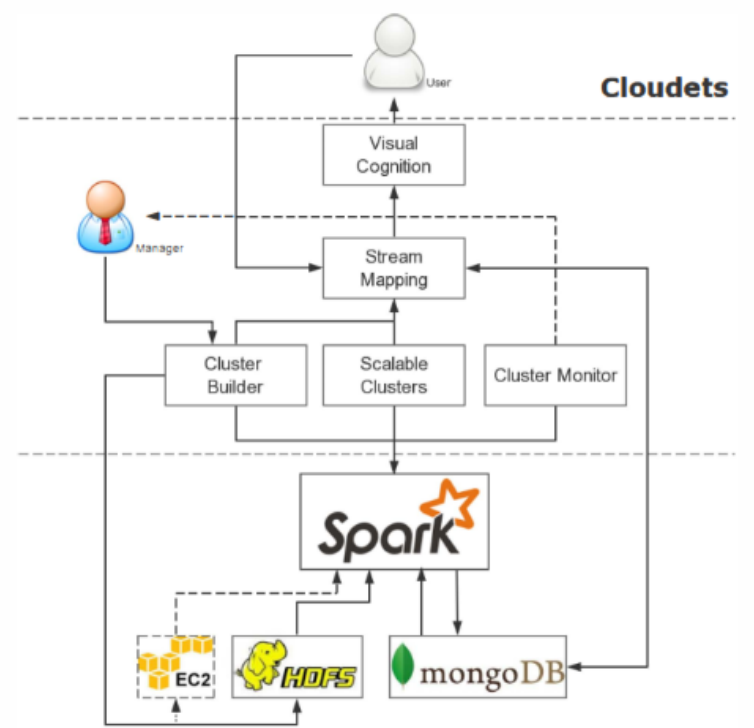

Figure 2: Cloudet Architecture (Rawai , 2013)

Suciu and Vulpe (2013) has described in their work about "Smart Cities built on resilient Cloud Computing and Secure Internet of Things (IoT)" According to them Cloud Computing and IoT are currently two of the most popular Information and Communication Technology (ICT) paradigms that are expected to shape the next era of computing. The convergence between Cloud Computing and IoT has become a hot topic over the last few years because of the benefits that IoT could have from the distributed nature of cloud computing infrastructures. Sarkar and Viramgami (2016) highlighted the parameters that need to be considered beyond Information and Communication Technology (ICT) for a smart city development. Sarkar and Jadav (2016) made an attempt to develop a cloud based project management information system (PMIS) for construction projects. Shawney and Maheshwari (2013) worked on developing design coordination using cloud based smart building elements.

\section{CASE STUDY}

Ahmedabad and Gandhinagar have been selected as the study area for this work as both the cities are selected for funding from the smart city mission under taken in AMRUT guidelines. For developing an existing city into smart city, major responsibility is with the local government authority. Ahmedabad Municipal Corporation (AMC) is working for development of Ahmedabad city and Gandhinagar Urban Development Authority (GUDA) is working for development of Gandhinagar City. AMC and GUDA works in different sectors for development of city which are listed below:
(a) Housing for urban and poor
(b) Environmental services
(c) Roads and transportation services
d) Healthcare services 
e) Town planning services

f) Other services

For development of smart cities development of the infrastructure in a smart manner is the basic and first step. Thereby, both the local authorities like AMC and GUDA need to focus upon the following applications of cloud computing during the development of the infrastructure of the two cities. The components and facilities of smart cities where the application of cloud computing can be done are:

(a) Urban transportation: Through real time data capture and the management of signals from video cameras and magnetic sensors installed in the road network, GPS systems could be used to track the location of public buses. Equally, social media monitoring systems could enable us to flag a protest organized on social networks and therefore facilitate the management of potential traffic jams by changing bus routes, modifying traffic light sequences and delivering information to drivers via mobile apps indicating approximate driving times and giving alternative routes.

(b) Urban waste management: By gathering data in real time from sensors that detect the container filling level and comparing to the historical data and usage trends it would be possible to forecast the ideal time for emptying each individual container and optimize waste collection routes.

(c) Public Safety: There may be improvement in the efficiency of police and fire services by capturing and correlating all the data coming from different systems installed in the city including surveillance cameras, emergency vehicle GPS tracking and fire and smoke sensors.

(d) Water management: By analyzing the data coming from metering systems, pressure or PH sensors installed in water supply networks and video cameras situated in water treatment plants it would be possible to optimize water management detecting leaks, reducing water consumption and mitigating sewer overflow.

(e) Energy management: With all the data coming from smart electric meters installed in customer's homes as well as meteorological open data platforms it would be possible to optimize energy production, depending on demand, which would help us to maximize the integration of renewable energy resources like wind and solar energy.

(f) Public sentiment analysis: By analysing social media networks and blogs and then using Big Data technologies, cities would be able to measure public opinion on key issues and services such as public transportation, waste management or public safety allowing them to priorities and shape policy.

(g) M2M and IoT solutions: These are an absolutely fundamental element of smart city projects. Installing thousands of sensors in public buildings (HVAC, lighting, security), energy management systems (smart meters, turbines, generators, batteries), transportation platforms (vehicles, lights, signage) and security systems (ambulances, video cameras, smoke detectors) allows us to use all of that data which is transmitted to a central server where it can be correlated and analysed with other sources of data turning it into meaningful information.

(h) Cost reduction: Big Data environments require a cluster of servers to support the processing of large volumes, high velocity and varied formats of data and the cloud pay-per-use model will be financially advantageous.

(i) Rapid provisioning/time to market: Big Data environments can be easily scaled up or down based on the processing requirements and the provisioning of the cloud servers could be done in real time.

(j) Flexibility/scalability: Big Data analysis in smart city environments requires huge computing power for a brief amount of time and servers need to be provisioned in minutes. This kind of scalability and flexibility can only be achieved with cloud technologies avoiding the required investments in very expensive IT infrastructure by simply paying for the consumed computing resources on an hourly basis. It is visualized that, if cities want to be smarter, more competitive and sustainable they need to leverage Big Data, together with M2M and Cloud Computing technologies in order to achieve their goals

A questionnaire was prepared on the basis of following sequence.

i) Knowledge about the Smart Cities

ii) Different sector of the Smart Cities

iii) Components of the Smart Cities

iv) Current challenges for Smart Cities

v) Importance of IT sectors in Smart Cities

vi) Various parameters for development of Smart Cities

vii) Necessity to implement Cloud Computing in Smart Cities

viii) Optimal use of Cloud Computing in Smart Cities

ix) Benefit to Smart City by using Cloud Computing

Following are the parameter, which are affected by using the cloud computing in different sectors of smart cities.

a) Cost Saving

b) Advance Technology

c) More flexibility

d) Better Functionality 
UGC Approved Journal

IARJSET

e) Complexity Reducing

f) Collaboration

g) Time Saving

h) Communication Ease

i) Improving Co-ordination

The questionnaire was circulated to 35 respondents out of which 30 respondents responded to this study. The respondents were primarily professionals associated with smart city projects. The responses were in a 5 point likert scale.

\section{CASE ANALYSIS}

Delphi method was followed for carrying out the questionnaire survey and collecting the responses. The collected responses were analysed to compute the relative importance index of the parameters considered for the application of cloud computing. The five-point scale ranged from 1 (not important) to 5 (extremely important) has been adopted and transformed to relative importance indices (RII) for each factor as follows:

$$
\mathrm{RII}=\frac{\Sigma \mathrm{r}}{\mathrm{A} * \mathrm{~N}}
$$

Where, ' $r$ ' is the rating given to each parameter by the respondents ranging from 1 to 5 where ' 1 ' is 'not important' and ' 5 ' is 'extremely important' parameter. ' $A$ ' is maximum rating (5 in this case) and " $N$ " is the total number of respondents.

The values of RII for some of the major parameters affecting the development of a smart city are presented in Table 1.

Table 1: RII Computation for Cloud Computing Based Parameters for Smart City Development

\begin{tabular}{|l|l|l|l|}
\hline S No. & Description of Parameter & RII & Rank \\
\hline 1 & Importance of involvement of cloud computing & 0.753 & 3 \\
\hline 2 & Improving communication through open data network & 0.613 & 6 \\
\hline 3 & Improving communication through city cloud & 0.713 & 4 \\
\hline 4 & Requirement of user friendly platform like mobile application & 0.833 & 1 \\
\hline 5 & $\begin{array}{l}\text { Requirement for smart employee monitoring system through Smart ID } \\
\text { /Biometric attendance / Mobile ID with GPS }\end{array}$ & 0.627 & 5 \\
\hline 6 & Importance of Data Mining for successful application of cloud computing & 0.813 & 2 \\
\hline
\end{tabular}

Table 2: RII Computation for Platforms used for Cloud Computing

\begin{tabular}{|l|l|l|l|}
\hline S No. & Description of Parameter & RII & Rank \\
\hline 1 & Software as a Services (SaaS) & 0.760 & 1 \\
\hline 2 & Platform as a Services (PaaS) & 0.667 & 2 \\
\hline 3 & Infrastructure as a Services (IaaS) & 0.660 & 3 \\
\hline
\end{tabular}

Table 3: RII Computations Based on the Requirements for Implementation of Cloud Computing for Smart City

\begin{tabular}{|l|l|l|c|}
\hline S No. & Description of Parameter & RII & Rank \\
\hline 1 & Ubiquitous Connectivity & 0.793 & 1 \\
\hline 2 & Collaboration Platform & 0.660 & 5 \\
\hline 3 & Internet of Things (IoT) & 0.760 & 3 \\
\hline 4 & Digitally Controlled Devices & 0.773 & 2 \\
\hline 5 & Open Data Access & 0.753 & 4 \\
\hline
\end{tabular}

Table 4: RII Computation for the Sectors of Smart City Suitable for Application for Cloud Computing

\begin{tabular}{|l|l|c|c|}
\hline S No. & Description of Parameter & RII & Rank \\
\hline 1 & Efficient Road Network & 0.633 & 3 \\
\hline 2 & Integrated Mass Rapid Transit Systems (MRTS) & 0.787 & 2 \\
\hline 3 & Intelligent Traffic Management System & 0.813 & 1 \\
\hline 4 & Other Smart Urban Infrastructure & 0.787 & 2 \\
\hline 5 & Cyber Security \& Surveillance & 0.627 & 4 \\
\hline
\end{tabular}


Table 5: RII Computation for Areas Where Application of Cloud Computing Can Create Improvement

\begin{tabular}{|l|l|c|c|}
\hline S No. & Description of Parameter & RII & Rank \\
\hline 1 & Haphazard Allocation of Fund & 0.760 & 1 \\
\hline 2 & Resource Allocation & 0.700 & 3 \\
\hline 3 & Encroachment Issues & 0.660 & 4 \\
\hline 4 & Ethical Planning of City & 0.480 & 5 \\
\hline 5 & Geological Data & 0.713 & 2 \\
\hline
\end{tabular}

The work flow diagram for implementation of cloud computing in a smart city project is presented in Fig. 3.

This framework is prepared to manage the project in each aspect via use of mobile application and the application is run through cloud. This framework is helpful to manage coordination between main authority and site staff or otherwise to maintain coordination between office and field. The framework includes all necessary information of the project which is helpful to the project progress like Daily Progress Report (DPR), financial status, Quality Assurance / Quality Control (QA/QC), Health Safety and Environment (HSE), inspection report, attendance report, material procurement status, planning and coordination.

There are several sectors on which AMC and GUDA are working to improve and manage city's infrastructure. A few of them have been selected for this study which are essential sectors to convert existing city into smart city. These are divided in six parts as shown in the workflow diagram (Fig 3). Each sector is having their own common framework where in a person in-charge can feed the data related to site progress.

Also, through information flow diagram it is possible to get the idea about the application and information pertaining to the flow of data in each part and how data mining process is to be done. Process flow diagrams are also helpful to make the application of cloud computing user-friendly. There are many process flow diagrams prepared in this research work like "Office Sign up Process Flow (OSPF)", "Office Login Process Flow (OLPF)", "GPS Attendance Process Flow (GAPF)", "Daily Progress Report Process Flow (DPRPF)", "Spot Inspection Process Flow (SIPF)" and "Spot Road Checking Process Flow (SRCPF)” which can help in implementing cloud computing for a smart city project.

\section{CONCLUSIONS}

According to the analysis carried out in this study, it has been observed that for RII computation for 'Cloud Computing Based Parameters for Smart City Development' the RII of 'Requirement of user friendly platform like mobile application (0.833) is maximum and hence is ranked 1.

Thus the project authorities (AMC and GUDA) involved in development of the smart city project need to make the maximum use of mobile application. Most of the project works carried out can be monitored with the use of mobile phones by retrieving the data stored in the cloud. 'Importance of Data Mining for successful application of cloud computing (RII : 0.813 ) has obtained $2^{\text {nd }}$ rank and thus need to be given due importance.

Similarly 'Importance of involvement of cloud computing (RII:0.753)', 'Improving communication through city cloud (RII : 0.713)', 'Requirement for smart employee monitoring system through Smart ID /Biometric attendance / Mobile ID with GPS (RII: 0.627)' and 'Improving communication through open data network (RII: 0.613) have obtained third, fourth, fifth and sixth rank respectively. AMC and GUDA also need to give due importance to these parameters. With respect to the 'Platforms used for Cloud Computing' the results of Delphi survey reveals that 'Software as a Services (SaaS) (RII : 0.760) is the first choice to the users followed by 'Platform as a Services (PaaS)' and 'Infrastructure as a Services (IaaS)'.

'Based on the Requirements for Implementation of Cloud Computing for Smart City' 'Ubiquitous Connectivity' need to be given more importance followed by 'Digitally Controlled Devices' and 'Internet of Things (IoT)'. With respect to the 'Sectors of Smart City Suitable for Application for Cloud Computing' the survey results reveal that AMC and GUDA need to focus on 'Intelligent Traffic Management System' followed by 'Integrated Mass Rapid Transit Systems (MRTS)', 'Other Smart Urban Infrastructure', 'Efficient Road Network' and 'Cyber Security \& Surveillance'.

Finally, it can be concluded that cloud computing can create improvement in the areas like 'Haphazard Allocation of Fund', 'Geological Data' 'Resource Allocation', 'Encroachment Issues' and 'Ethical Planning of City'. 


\section{UGC Approved Journal}

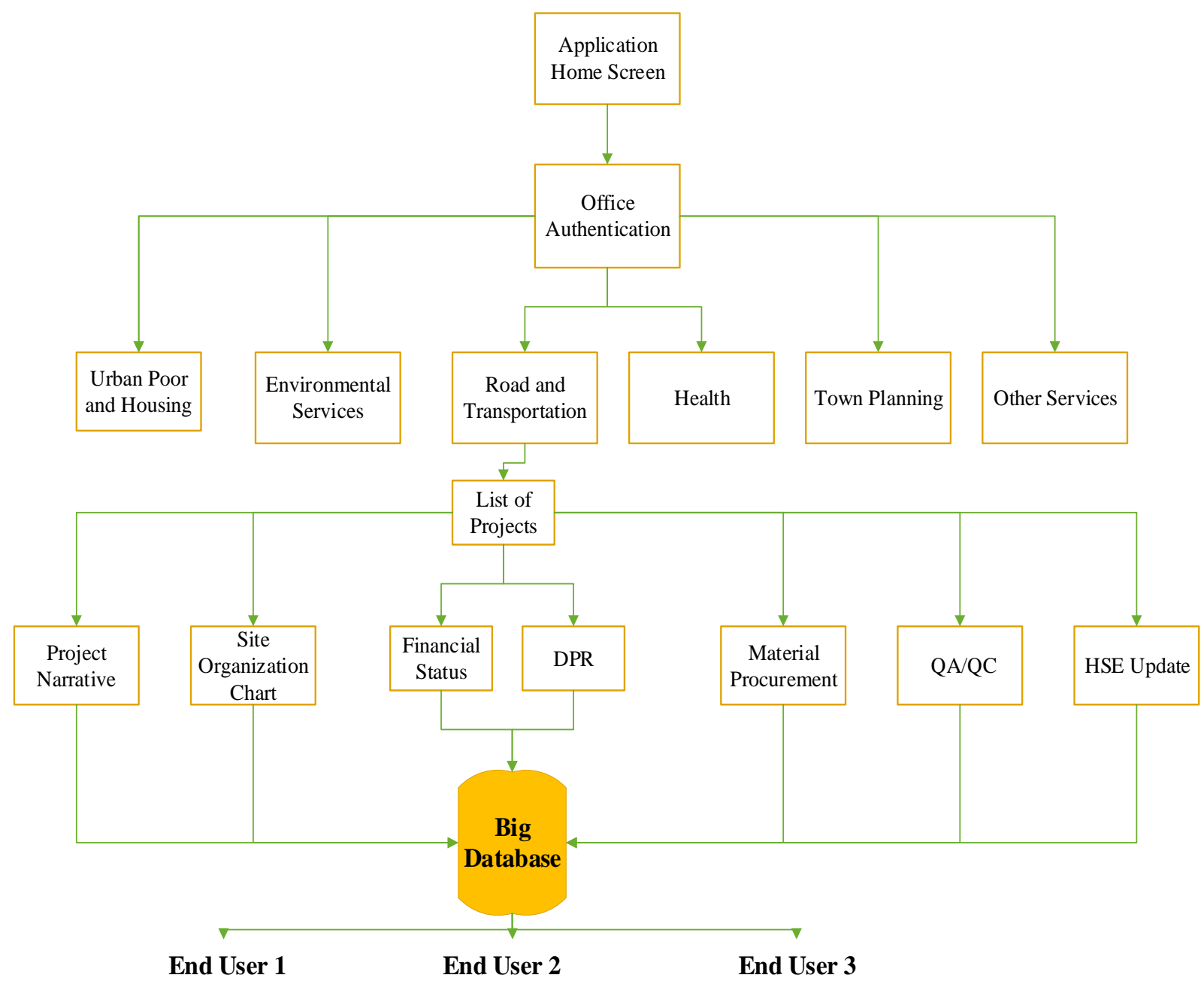

Fig 3 : Work Flow Diagram for Implementation of Cloud Computing in Smart City

\section{REFERENCES}

[1] Nowicka, K. (2014), 'Smart City logistics on cloud computing model', 1st International Conference Green Cities, Vol 1, pp266-280.

[2] Rawai, N. (2013) 'Cloud Computing for Green Construction Management' Faculty of Civil Engineering, Universiti Teknologi Malaysia, Malaysia, Vol 14, pp 24-31.

[3] Sarkar, D and Viramgami, R (2016) 'Smart Cities: A Study of Prospects Beyond Information and Communication Technology (ICT)' International Advanced Research Journal in Science Engineering \& Technology, Vol.3(2), pp. 36-41.

[4] Sarkar, D and Jadav, B.S. (2016) 'Cloud based project management information system (PMIS) for construction projects' International Journal of Civil and Structural Engineering, Vol. 6(3), pp. 233-242.

[5] Sawhney, A. and Maheswari, J. (2013), 'Design Coordination Using Cloud-based Smart Building Elements Models', International Journal of Computer Information Systems and Industrial Management Applications, Vol 5, pp445-453.

[6] Suciu, G. and Vulpe, A. (2013) 'Smart Cities Built on Resilient Cloud Computing and Secure Internet of Things' Department University Politehnica of Bucharest Bucharest, Romania, Vol 39, pp 35-42. 